\title{
Embarazo ectópico molar tubárico: a propósito de un caso clínico
}

\author{
Encarnación Arévalo Reyes ${ }^{1}$, Amelia Vizcaíno Martínez ${ }^{2}$, María Luisa Vizoso Pérez 3 , \\ Rafael Enrique Sotelo Avilés. ${ }^{2}$ \\ ${ }^{1}$ Médico Residente, Servicio de Obstetricia y Ginecología, Hospital Universitario San Cecilio. ${ }^{2}$ Médico adjunto, Servicio \\ de Obstetricia y Ginecología, Hospital Universitario San Cecilio. ${ }^{3}$ Médico Residente, Servicio de Anatomía Patológica. \\ Hospital Universitario San Cecilio. Granada. España.
}

\section{RESUMEN}

Introducción: La incidencia de gestación ectópica es 20/1000 embarazos. La mola hidatiforme ocurre en $1 / 1000$ embarazos. Los casos de mola hidatiforme en embarazos ectópicos albergados en las trompas de Falopio constatados en la literatura mundial son excepcionales. Objetivo: Presentamos un caso clínico de embarazo ectópico molar tubárico y revisión de la literatura. Conclusión: La enfermedad trofoblástica gestacional asociada a embarazo ectópico es un entidad extremadamente rara que debe tenerse en cuenta por su trascendencia.

\section{PALABRAS CLAVE: Embarazo ectópico molar, embarazo ectópico, embarazo tubárico, mola hidatiforme}

\section{SUMMARY}

Introduction: The incidence of ectopic pregnancy is 20/1000 pregnancies. The hidatidyform mole occurs in about $1 / 1000$ pregnancies. The cases of hidatidyform mole in ectopic pregnancies located in the Fallopian tube collected in world literature are exceptional. Objective: We present a clinical case of an ectopic molar pregnancy in the tubes and a literature review. Conclusion: The trophoblastic pregnancy disease associated to an ectopic pregnancy is an extremely rare entity that should be considered because of its transcendence.

KEY WORDS: Ectopic molar pregnancy, ectopic pregnancy, tubal pregnancy, hidatidyform mole

\section{INTRODUCCIÓN}

La incidencia de la mola vesicular varía ampliamente a nivel mundial, según la zona geográfica y los estudios consultados, oscilando desde 1 caso por cada 100 embarazos en países como India, hasta 1 caso por cada 2000 embarazos en EEUU, según algunas series (1). Por otro lado, la inciden- cia de embarazo ectópico se estima en torno a un 1 por cada 100 embarazos (2). La conjunción de ambas entidades es mucho más rara y, por tanto, tiene una incidencia mucho menor, estableciéndose en aproximadamente 1,5 casos por millón de embarazos (1).

En la literatura científica recogida, a nivel mundial se han constatado entre $40-43$ casos $(2,3)$. 
Porcentualmente, la incidencia de la mola hidatiforme alojada a nivel tubárico, varía entre 0,5 y $0,6 \%$, según algunos autores, pero se cree que podría ser menor según revisiones realizadas posteriormente a nivel histológico (3).

Presentamos el caso clínico de una paciente diagnosticada inicialmente como embarazo ectópico complicado, y que posteriormente se confirmó un embarazo ectópico tubárico molar.

\section{Caso clínico}

Paciente de 32 años, secundigesta, con los antecedentes personales de un parto eutócico previo y colitis ulcerosa en tratamiento. La paciente había sido tratada 15 días antes en otro centro hospitalario con 2 dosis de metotrexate por sospecha de embarazo ectópico, con buena tolerancia y respuesta, presentando cifras decrecientes de beta gonadotropina coriónica (BhCG) $(8.149 \mathrm{mUl} / \mathrm{ml}$; $4.920 \mathrm{mUl} / \mathrm{ml} ; 1.084 \mathrm{mUl} / \mathrm{ml} ; 188 \mathrm{~m} \mathrm{Ul} / \mathrm{ml})$. Ingresa en nuestro Servicio por dolor hipogástrico, de inicio súbito, metrorragia y malestar general.

A la exploración física destaca sangrado vaginal leve y dolor abdominal moderado sin signos de irritación peritoneal, manteniéndose clínicamente estable. Ecográficamente, se apreció útero normal con línea endometrial fina, trompa derecha engrosada con imagen adyacente de unos $2 \mathrm{~cm}$ de diá- metro, que por sus características era compatible con coágulo; ovarios de forma y tamaño normales y escasa cantidad de líquido libre en fondo de saco de Douglas. Se realiza nueva determinación de BhCG sérica obteniendo un valor de $100 \mathrm{mUl} /$ $\mathrm{ml}$. Parámetros analíticos sanguíneos estables (hemoglobina: 10,8 g/dl; hematocrito: $31,8 \%$ ). Ante los datos analíticos, hallazgos por imagen y el no deterioro hemodinámico de la paciente se decide ingreso hospitalario para observación y conducta expectante.

Tras 2 días de ingreso, en los que la paciente estaba estable, comienza con un súbito empeoramiento clínico, hipotensión arterial, signos de irritación peritoneal y nuevo descenso de los parámetros analíticos (hemoglobina: $8,7 \mathrm{~g} / \mathrm{dl}$; hematocrito: $26,1 \%$ ), motivo por lo que se decide intervención quirúrgica, pese al descenso notable de BhCG. Se practica laparoscopia bajo anestesia general, evidenciándose embarazo ectópico complicado a nivel de istmo tubárico (Figura 1), así como una cantidad leve-moderada de hemoperitoneo y coágulos organizados ubicados en fondo de saco de Douglas. Se realiza salpingectomía derecha y lavado de cavidad abdominal. El post operatorio cursa con buena evolución, siendo dada de alta a los 3 días, con resultado pendiente de anatomía patológica. Se prescribe anticoncepción hormonal oral combinada para garantizar un riguroso seguimiento clínico.

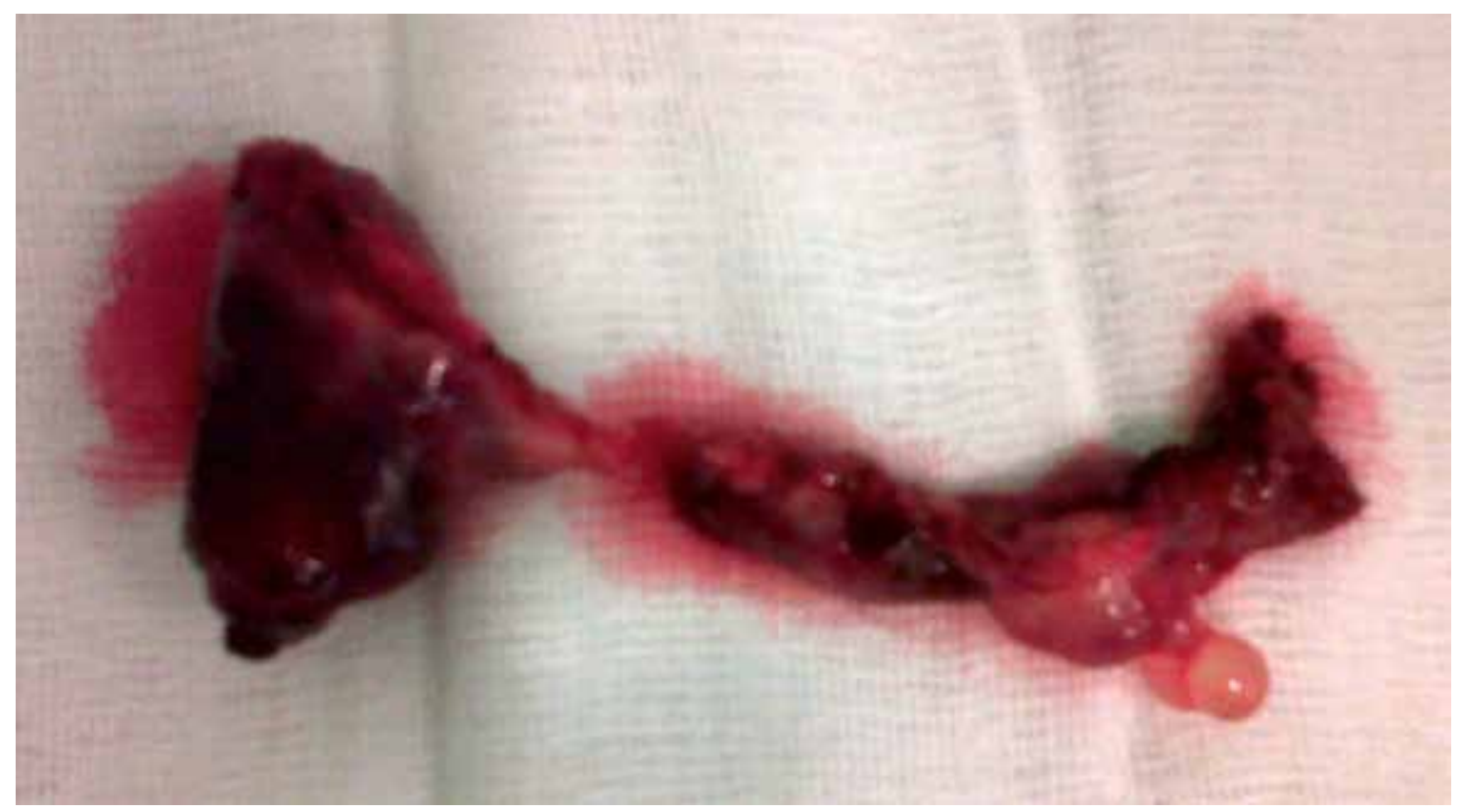

Figura 1. Pieza quirúrgica extirpada, donde puede apreciarse, de izquierda a derecha, la presencia de una trompa de Falopio y en su extremo distal el saco gestacional que contenía una mola parcial. 
Diez días tras la intervención quirúrgica, el estudio anatomopatológico informa: gestación ectópica tubárica intraparietal con cambio molar parcial (Figura 2 y 3). Se cita a la paciente para completar estudio, mediante radiografía antero-posterior de tórax (sin hallazgos patológicos), y nueva determinación de BhCG $(0,9 \mathrm{mUl} / \mathrm{ml})$. Se continúan los controles analíticos seriados, constatándose un descenso progresivo hasta obtener 3 valores de BhCG negativos $(<0,1 \mathrm{mUl} / \mathrm{ml})$, permaneciendo asintomática y los valores de BhCG indetectables en los sucesivos doce meses, periodo durante el cual permaneció con anticoncepción hormonal oral combinada.

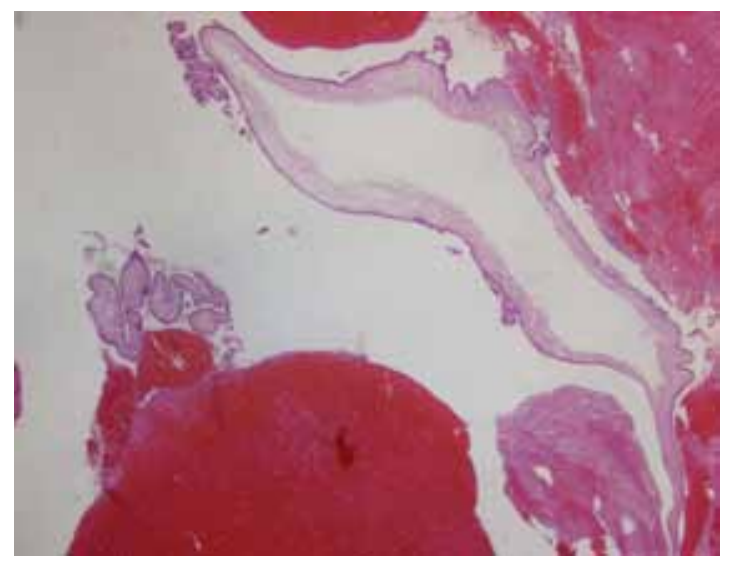

Figura 2. Mola parcial muestra vellosidad voluminosa y engrosada que presenta una cisterna central. Se identificó en la superficie de la vellosidad proliferación trofoblástica focal (H\&E, aumento x2).

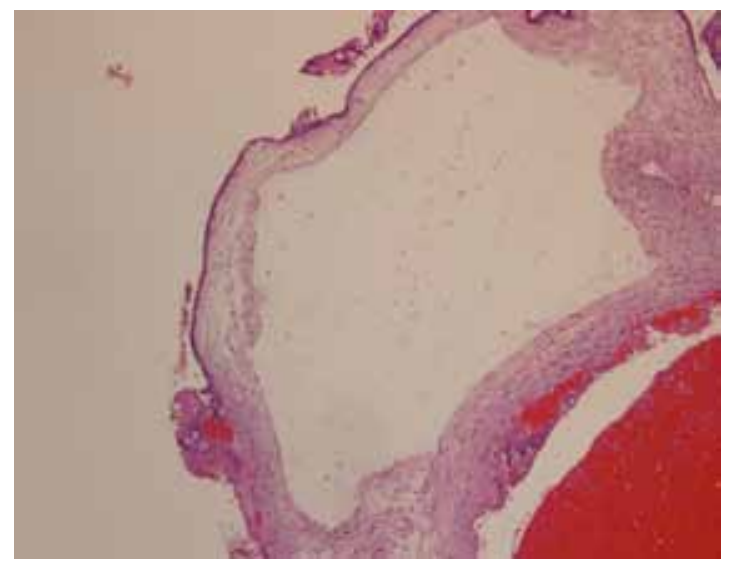

Figura 3. Edema focal en estroma y formación de cisterna central (H\&E, aumento x4).
En la actualidad, tras haber transcurrido 20 meses, la paciente se encuentra nuevamente embarazada, con una gestación conseguida espontánea y normo evolutiva.

\section{DISCUSIÓN}

La enfermedad trofoblástica gestacional está constituida por un abanico de patologías que se caracterizan por una proliferación anómala de las células trofoblásticas, las cuales poseen potencial maligno. Incluye a la mola hidatiforme (parcial o completa), caracterizada por un crecimiento anormal de tejido trofoblástico consecuencia de una fecundación aberrante y al tumor trofoblástico gestacional.

El embarazo molar es una gestación anormal, resultado de una fertilización defectuosa, caracterizada por la presencia de cambios hidrópicos que afectan las vellosidades placentarias, así como hiperplasia trofoblástica. Puede ser mola completa o parcial, siendo en el primer caso la mayoría diploides y de origen paterno (46XY) resultado de la fertilización de un ovocito sin DNA por un espermatozoide haploide que se duplica una vez fecundado; mientras que en el segundo caso la mayoría son triploides (47XXY), procedentes de una fertilización anómala de un ovocito haploide con una zona pellucidum defectuosa por un espermatozoide haploide (1).

Se estima que la incidencia de embarazo ectópico en Europa es del 1\%, mientras que la mola hidatiforme se encuentra entre 1-2 por 1000 gestaciones. La conjunción de ambas entidades, la presencia de una mola hidatiforme ectópica, de localización tubárica, es mucho más rara, habiéndose publicado sólo unos 43 casos en toda la literatura mundial (1).

Los factores de riesgo asociados al desarrollo de un embarazo ectópico, son comunes para el desarrollo de un embarazo molar tubárico, como son el antecedente de un embarazo ectópico previo, enfermedad inflamatoria pélvica anterior, ligadura tubárica bilateral, cirugía sobre trompas de Falopio o la presencia de dispositivos intrauterinos y, en los últimos años, las técnicas de reproducción asistida (1).

A nivel clínico, es indistinguible la presencia de un embarazo ectópico o de una mola tubárica, dada la similitud sintomática de ambos $(4,5)$, como es el dolor en hipogastrio (localizado o no a nivel ilíaco), o el sangrado vaginal. Se ha publicado incluso, que la presencia de un embarazo molar a nivel tubárico, presenta mejor pronóstico que el embarazo molar intrauterino, pues debido a la gran proliferación del 
trofoblasto, la mola tubárica sufre una rotura más temprana, con lo cual se diagnostica y trata con mayor antelación (2).

Para establecer un diagnóstico inicial, se precisa la suma de la clínica junto con una determinación seriada de BhCG. El estudio ecográfico puede orientar el diagnóstico, en cuanto a la imagen que produce la mola ("en copos de nieve") (2), pero se ha visto que no es muy objetiva y poco específica (6-9). Además, la sospecha ecográfica de la presencia de un embarazo molar es más evidente en caso de mola completa que mola parcial, por la mayor cantidad de trofoblasto y la ausencia de embrión en el primero.

El examen histopatológico de la muestra obtenida tras el tratamiento quirúrgico del caso es el que aporta el diagnóstico definitivo $(4,7,10)$. Así, el hallazgo de proliferación trofoblástica circunferencial, cambios hidrópicos o cariorrexis en el estroma orienta el diagnóstico hacia la presencia de mola. Hay que ser cautos y evita diagnósticos falsos positivos, especialmente en embarazos ectópicos precoces, en los que también se ha observado una mayor proliferación del trofoblasto en comparación con gestaciones intrauterinas (7).

Por otro lado, para precisara aún más el diagnóstico, se puede recurrir á la determinación de DNA mediante citometría de flujo, con la finalidad de distinguir si se trata de una mola completa o parcial, en caso de duda ante los hallazgos histológicos $(4,7,10)$. Por tanto, la suma de todos estos procedimientos diagnóstico-terapéuticos, es lo que nos permite un diagnóstico seguro final. En cuanto al tratamiento, hay unanimidad en que la solución es quirúrgica, siendo predominante la vía laparoscópica frente a la laparotómica.

Se estima que, el desarrollo de un tumor del trofoblasto, tras la evacuación de la mola, se encuentra en torno a un $20 \%$ según algunas series (2), por lo que está indicado el seguimiento con titulaciones periódicas de BhCG hasta su negativización, radiografía de tórax y planificación familiar segura, al menos durante un año, a fin de garantizar un control objetivo de dicha patología.

\section{CONCLUSIÓN}

El embarazo ectópico molar de localización tubárica es una entidad de muy baja incidencia. No obstante, y especialmente en pacientes con factores de riesgo para el desarrollo de embarazo ectópico, debe tenerse en cuenta en el diagnóstico diferencial con esta entidad. Es fundamental un diagnóstico de sospecha y tratamiento quirúrgico temprano en el control de complicaciones agudas, así como un minucioso seguimiento posterior, ante la posibilidad de desarrollo de un coriocarcinoma. De ese modo, la fertilidad de la paciente quedará intacta, pudiendo ser restablecida, tras un tiempo prudencial, con total normalidad.

\section{REFERENCIAS}

1. Gillespie AM, Lidbury EA, Tidy JA. The clinical presentation, treatment and outcome of patients diagnosed with possible ectopic molar gestation. Int J Gynecol Cancer 2004;14:366-9.

2. Araujo L, Guerrero B, Caripidis J, García L, Garrido M. Embarazo molar tubárico. Reporte de un caso. Gac Méd Caracas 1998;6(4):555-7.

3. Rees HC, Paradinas FJ. The diagnosis of hydatidiform mole in early tubal ectopic pregnancy. Histopathology 2001;39(3):320-1.

4. Burton JL, Lidbury EA , Gillespie AM, et al. Over-diagnosis of hydatidiform mole in early tubal ectopic pregnancy. Histopathology 2001;38:409-17.

5. Siozos A, Sriemevan A. A case of true hydatidiform mole and literature review. BMJ CaseReports 2010;doi:10.1136/bcr.07.2009.2123

6. Davari F, Shir Ali E, Rahmanpour Hetal. Molar pregnancy presents as tubal ectopic pregnancy. Int J Fertil Steril 2011;4(4):184-6.

7. Borah T, Raphael V, Panda S et al. Ectopic Molar Pregnancy: a rare entity. J Reprod Infertil 2010;11(3):201-3.

8. Govind A, Lakhi A. A molar masquerading as an ectopic pregnancy in the early first trimester: a salutary lesson. Int J of Woman's Health 2012;4:423-5.

9. Flores C, Barboza O, Vidal O, Morales F. Embarazo ectópico molar cornual. Caso clínico. Rev Chil Obstet Ginecol 2010;75(2):133-136.

10. Chauhan S, Diamond MO, Johns DA. A case of molar ectopic pregnancy. Fertil Steril 2004;81:1140-1. 